\title{
The Scholarship of Teaching and Learning: Help for Academic Tour Guides
}

\author{
Rachael Saathoff \\ BS Candidate \\ Buffalo State University
}

\begin{abstract}
The presence of scholarship of teaching and learning (SoTL), or its absence, has greatly impacted my undergraduate studies. While professors are experts in their subject matter, they do not always know how to reach students. SoTL provides resources to address such disconnects. Just-in-time teaching (JiTT) is one example

of a SoTL-informed teaching assignment that can help students learn more effectively. Because SoTL helps professors understand how students learn, it can encourage excellence in the classroom.
\end{abstract}

\section{Introduction: Why Talk about SoTL?}

As an undergraduate, I have not done extensive research into scholarship of teaching and learning (SOTL). Initially, I felt woefully unqualified to write anything about SoTL. What could I possibly have to say about "practices that engage teachers in looking closely and critically at student learning for the purpose of improving their own courses and programs" (Hutchings, Huber, \& Ciccone, 2011, p. 7)? Now I realize my learning experiences as a student are essentially the basis for any SoTL research.

Professors have a difficult job. They are responsible for teaching material and serving as role models. Their classrooms are a meeting place of diverse learning styles and a wide spectrum of expectations, skills, motivations, and hopes. In many ways, a professor is much like the guide of a noisy group of tourists. A good guide reveals the interesting parts of the tour to the tourists-something that not all guides do effectively. Guides need training and help to learn how best to show tourists around a city like Rome or Paris. SoTL serves a similar purpose: it helps professors guide their students effectively through subjects like British Literature and European History. SoTL offers a scholarly approach to teaching (Healey, 2010) that encourages excellence in the classroom, bridges the gap in understanding between the teacher and the student, and improves the quality of education.

\section{The Need for SoTL}

When I began my college career, I fully expected exclusively lecture-based classes, filled with redundant content from a textbook. Sadly, I was not entirely wrong: I took a number of courses held in large lecture halls that sucked the life out of interesting content. These courses are the equivalent of touring the Metropolitan Museum of Art with the painfully unengaging economics teacher in Ferris Bueller's Day Off (1986). This amazing collection of human artwork and culture turns into uninteresting artifacts with no relevance for tourists, as the guide plows through material in a monotone voice, not even bothering to actually show interest.

Fortunately, not all lectures are like this. Some result in an environment that encourages students to engage with the material but, first, students must be responsible for knowing the simple, textbook stuff. For example, if reading Scott Fitzgerald's The Great Gatsby, students should know the main characters' names, the color of the light at the end of Daisy's dock, and what happens plotwise. The professor can then effectively take the roof off of the text by giving students a 
deeper understanding of the inner workings of the book. With The Great Gatsby it helps to (1) know the historical, political, and societal backgrounds of the time; (2) look closely at the structure of the story; (3) examine the author's use of language to further the narrative, and (4) introduce different literary interpretations of the text. These steps show students what is beneath the roof or surface of a text. Here, the professor is less a tour guide than a coach or teacher training students and encouraging excellence. A good lecture allows a professor to hold students accountable for the reading while still deepening their understanding. Student understanding must move beyond simple regurgitation and memorization to truly achieve the status of excellence in the classroom (Ramsden, 2003). SoTL helps a professor determine how best to lecture effectively and encourage students to excel in class.

Though I cannot deny the evidence claiming straight lecture ultimately does not help students learn best (Healey, 2010), I have developed a preference for professors who primarily lecture, chiefly because some professors use "discussion" to have students repeat what he or she wants to hear. Others use discussions as a cover for lack of preparation or for extended, personal, off-topic rants. Professors can also lose control, finding themselves barely able to rein in off-topic, at times disrespectful, student-led discussions. Thus I concluded two major things: First, discussion-based classes can result in students metaphorically bashing each other over the head with opinions. Second, the lack of structure can allow a class to run away from a professor, not unlike small children loudly fighting with each other while the parents fail to address the inappropriate public behavior. If forced to pick, I prefer a mind-numbing, disorganized lecture to the aimless ramblings of my classmates. Professors who skillfully lead class discussion with awareness of student learning and understanding have learned to bridge the gap.

I have witnessed several well-functioning courses where discussion enhanced my own understanding. One course, Ethnic Minority Literature, taught me how to read a text with certain passages in mind to discuss in class. I knew the reading would allow me to be part of the classroom community created and led by the professor. Subsequently, I really enjoyed class time. In my experience, effective professors encourage student participation, and they are able to navigate and guide discussion in a way that focuses on important course content. Professors would be wise to note relevant literature (Barkley, 2010; McKeachie, 1994; Ramsden, 2003) to improve the quality, enjoyment, and effectiveness of their classes.

I have a great deal of respect for my professors. Teaching is hard. To do it well requires skill, practice, and hard work, just as in any other profession. A professor may have a thorough understanding of a topic, while students do not yet have the tools to tackle the issues. Worse, students often feel overwhelmed and confused. Faculty do not always know how best to address those issues. SoTL helps professors understand how students learn. For example, SoTL work has shown that introducing specific types of assignments can encourage students to come to class prepared to learn from the professor. One such assignment is called Just-in-Time Teaching.

\section{Just-in-Time Teaching (JiTT)}

In Spring semester of my first year at Buffalo State University, I encountered just-in-time teaching (JiTT), a SoTL informed method. JiTT is a pedagogical strategy that strives to "help students structure their out-of-class efforts and to get more out of precious in-class student-instructor face time... [allowing] the students to do preparatory work between classes with ample time to reflect, and [giving] the instructor time to prepare lessons with timely student input" (Novak \& Patterson, 2010, p. 5). Typically, such strategies are used in courses that require large amounts of reading. Thus far, my impression of primary text-based classes had not been entirely favorable. Class discussion often failed because many students had not done the reading, and professors resorted to 
stepping students through an entire text by reading passages aloud and explaining accordingly. Sitting in class while the professor summarized for the students who had not read drove me crazy. I wanted class time to be spent more productively; I wanted to actually learn something.

In my Professional Ethics course I encountered JiTT in the form of abstracts. The professor required us to write abstracts, relatively short in length and capping at 150 words. They were assigned two to three times a week. Eventually I developed a begrudging appreciation for this teaching technique. Now I am convinced it is one of the most effective ways to approach a course that requires vast amounts of scholarly reading. JiTT encourages students to work on evaluation, clarity, conciseness, understanding, and various other skills, depending on the way a professor shapes the assignment. Abstracts are also easily assessed, with the benefits outweighing the extra time spent by the professor. I have seen a wide variety of JiTT assignments, ranging from journals to short essay responses to applicable questions. In particular, abstracts stick out as a unique example of JiTT benefits: They cultivated habits that have served me well in practically every class thereafter. In essence, JiTT is an excellent example of SoTL at work, encouraging student learning.

Short assignments like abstracts forced me to evaluate necessary information as I read texts for class. In Professional Ethics class, there were as many as three articles a week with 10-40 pages in each reading. To condense that much information into 150-word abstracts took attention and work. Then, when it came time to write my abstract, I simply reread the article based on my notes. I would evaluate the article, trying to include what I considered to be the most important parts of the author's argument. At times, I had to pick between examples or phrases, but the process was helpful because I came to class equipped with my own summary and ready to participate

JiTT promoted good reading practices by forcing me to come to terms with the author's argument, but it also improved my writing practices. In particular, JiTT encouraged me to embrace brevity. For someone like me, word counts or page limitations are healthy. By forcing me to summarize content in a clear and concise manner, abstracts gave me the ability to communicate well in fewer words. To get to the point where I could summarize in $\mathbf{1 5 0}$ words, I had to have a full grasp of the concepts and arguments in the article. Then, pulling from synonyms, I translated phrases or words or arguments into shorter, clearer sentences. If an article made eight main points using different grammatical structures, openings, and paragraphs, I restructured the argument so all points supported subject-verb agreement. Such a process helped me to develop an easier-to-follow writing style.

Evaluation and conciseness both require a student to pursue understanding rather than regurgitation. Currently, students like me are saturated in an education system and, for that matter, a culture that encourages, even demands, us to voice our thoughts on matters. We are encouraged to pursue our individual tastes, preferences, goals, and dreams. While these are not necessarily bad things to pursue, they can sometimes come at the cost of true understanding. For example, if a student is assigned a book for a class, his or her automatic response is to read through the lens of personal opinion. Since the purpose of the abstract is ultimately to convey what a text says, not what a student thinks about it, abstracts train students to think differently when reading. Instead of simply reacting to a text, students must respond by explaining what they have digested. Abstracts leave no room for personal opinion. They intentionally aim to have students pursue understanding of the text before voicing opinions or disagreements, leading to much more fruitful class discussions.

Additionally, the frequency of assignments ends up being one of the most helpful aspects of writing these abstracts, which becomes normal, habitual, and much easier as the semester progresses. Students know that they will be required to summarize central arguments of each of the readings. They are expected to read each text carefully and give some thought to how best to present its essential 
insights. Before long, this becomes a regular part of the course. Class discussions are more fruitful because students are familiar with the reading. Moreover, because of regular feedback, it is easy to familiarize oneself with a professor's goals. In courses not utilizing JiTT, I have often felt confused about a professor's expectations, and those same professors tend to return assignments far later than projected, or to provide little feedback. The lack of frequency, coupled with the late feedback, results in frustration on my end as I try to figure out the workings of the class. I can imagine that assignments like abstracts might be unappealing to a professor. After all, receiving dozens of abstracts multiple times a week results in mountains of grading. One solution is to grade them at random, giving students credit for turning abstracts in. Overall, feedback on JiTT assignments pays off in student learning.

\section{JiTT: Adaptability and Flexibility}

JiTT aids professors invested in helping students learn to use class time productively, increase student skills in evaluation, clarity, and conciseness, and in supporting pursuit of knowledge and helpful habits. These benefits are not confined to abstracts; other forms of JiTT exist. One course, History of Ethics, used questions, due the night before class, to guide student reflection on the reading. This allowed the professor to shape discussion to fit student needs based on the level of comprehension demonstrated. Though they did not require as much evaluation as abstracts since the questions were significantly more relaxed, the questions allowed more reflection and required students to connect dots between different philosophical authors. Journals, another JiTT assignment, can also log student reflections on readings such as short stories or poems. Depending on the professor's guidelines, journals focused on themes or asked students to compare different works. Ideally, they allowed students to respond more freely than an abstract or a guided question. They encouraged student exploration, giving more opportunities to pursue what interested them in the readings. The various forms of JiTT assignments are easily adaptable to meet a professor's needs. They can be altered or adjusted to encourage different skills or habits, such as reflection or comparison. Whatever the form, JiTT can shape the way a student understands content, writes about content, and approaches content through reading. Ultimately, they make students more responsible for learning and help professors address real issues that impede learning.

JiTT has become one of my favorite aspects of my courses. I know many students complain about the frequency of assignments. In fact, I was one of them, but this objection can be shortsighted. In class after class, I have seen how helpful JiTT can be. It helps students to keep up with reading, and it can encourage students to approach a text in different ways depending on the professor's desires and the purpose of the course. JiTT is a great tool for professors. And I am not the only one who seems to think so: "Indeed, one advantage of JiTT is that it encourages students to read course-related material before class, spreading their work more evenly over the semester, often a significant step for students who believe that it is better to wait for the instructor to explain the course material" (Simkins \& Maier, 2010, p. xiii). I have seen a wide variety of JiTT, ranging from journals to short essay responses to application questions. Professors altered assignments to suit the needs of the course material. But in each case the JiTT enhanced my learning and made class time more meaningful. It will be up to SoTL to fine-tune and evaluate the various forms of JiTT, but I think as a whole anything that encourages evaluation, conciseness, and understanding will help students and teachers reach that goal of learning. JiTT is SoTL at its finest. Not only does it address the issue of encouraging students to read, but it also gives them a useful skill that will help them beyond the course. It serves the student and the teacher. 


\section{Conclusion}

From my point of view, the professor's role is somewhere between that of a textbook and an autobiography. Just as tour guides should know more than what is on the travel brochures, professors are expected to know certain things as professionals; those things extend far beyond the scope of one course. If professors only served as textbooks, then an entirely self-taught education becomes believable. This is why autobiography is important. The most effective tour guides have lived in and experienced a city for years; they are a wealth of stories and information. Similarly, professors serve not only as a resource for students but also as mentors and role models at a professional level. The biologist, for example, speaks as an expert in his or her field, and not just as someone who knows things about biology. This is where a professor goes from being a textbook to an autobiography.

As an autobiography, a professor can pull from their professional experiences to aid students. For example, hearing a professor discuss Europe nostalgically as we read British literature made me want to read more on my own. The experience added to what I was reading. Just as the tour guides can advise tourists not to dine at a bad restaurant where they themselves once made the mistake of eating, professors can pull from their autobiographies to warn or encourage students to not make the same mistakes. A well-written autobiography can provide a reader with more than just facts; it may provide experiences and stories that spark a reader's interest and open up a world previously unknown. Autobiographies can captivate us because they give us insight into what it can be like to be another person in another field. This applies to professors, too. A "textbook professor" can recite facts, but an "autobiography professor" has experience in the content area that can ignite passion and enthusiasm for that content.

This is why SoTL matters: Both well-written textbooks and autobiographies have a strong sense of their audience and communicate effectively. SoTL helps professors produce courses that bridge the gap between textbook facts and autobiographical stories. It trains professorial tour guides by showing them how to best reach their audience. Misunderstanding between the professor and students may be due to any number of factors; that is why SoTL is a viable and valuable resource for the professional teacher. It helps the autobiographical (or textbook) teachers to integrate textbook (or autobiographical) content in a meaningful way for students, by giving them the tools or habits to cultivate an environment in which students can flourish, improving their education accordingly. JiTT is only one example of the many resources available to professors. All they have to do is pursue SoTL research, and I think they will find that they can take their "tourists" through the wonders of a course in a way that interests and engages students. Perhaps those tourists will fall in love with the tour and, in turn, become experts themselves.

\section{References}

Barkley, E. F. (2010). Student engagement techniques: A handbook for college faculty. San Francisco: Jossey-Bass.

Healey, M. (2010). Developing the scholarship of teaching in higher education: A discipline-based approach. Higher Education Research \& Development, 19(2), 169-189.
Hughes, J. (Director). (1986). Ferris Bueller's Day Off [Motion Picture]. United States: Paramount Pictures.

Hutchings, P., Huber, M. T., \& Ciccone, A. (2011). The scholarship of teaching and learning reconsidered: Institutional integration and impact. San Francisco: JosseyBass. 
Novak, G. \& Patterson, E. (2010). An introduction to just-in-time teaching (J iTT). In S. Simkins \& M.H. Maier (Eds.), Just-in-time teaching: Across the disciplines, across the academy (p. 3-23). Sterling, VA: Stylus Publishing, LLC.
Ramsden, P. (2003). Learning to teach in higher education. New York: Routledge Falmer.

Simkins, S. \& Maier, M. H. (Eds.). (2010). Just-in-time teaching: Across the disciplines, across the academy. Sterling, VA: Stylus Publishing, LLC.

Rachael Saathoff, a Buffalo, NY native, plans on graduating from Buffalo State University in Spring 2014 with a B.S. in English Education (7-12) and a minor in philosophy. She is a member of the Muriel A. Howard Honors Program, attending various events and enrolling in honors seminars. Her academic interests include philosophy, literature, character education, pedagogical methods, writing, ethics, and the history of the English language. She received the 2013 Outstanding Minor in Philosophy award from the Department of Philosophy and an Undergraduate Summer Research Fellowship for 2013 to study character ethics and philosophy of education through the Office of Undergraduate Research. 